\title{
Teaching Vocabulary through CAVI: An Action Research Project
}

\author{
Rifa Anjum, MS Scholar, ELDC \\ Dr Shumaila Memon, Associate Professor, Mehran UET Jamshoro \\ Dr Habibullah Pathan, Associate Professor, Mehran UET Jamshoro \\ Dania Wasi, MS Scholar, ELDC \\ Dr Muhammad Arslan Raheem, Assistant Professor, University of Education, Pakistan \\ Faiza Mushtaq, Lecturer, National University of Modren Languages, Multan, Pakistan
}

\begin{abstract}
Vocabulary learning is a fundamental aspect of language learning for ESL or EFL learners. The speedy modifications within the advancement of technological and pedagogical ways have proven to be quite captivating for instructors. Therefore, educational practitioners attempt to induct these digital and technological sources in their ESL or EFL classrooms for teaching diverse language skills. This study evaluates ESL learners' performance after computer-assisted vocabulary instruction (CAVI hereafter) induction for about ten (10) weeks. In addition, this experimental study also aims to serve the purpose to examine the attitude of the learners towards CAVI practices. It is an action research (AR) project, where convenience sampling has been used to sort out the target population $(n=74)$ from an Elite Private School (EPS hereafter) in Hyderabad, Sindh, Pakistan. Moreover, the collected data has been analyzed statistically through SPSS software. According to the results, the learners expressed their eagerness to learn vocabulary through digital resources, and data witnessed that their overall performance pre and post CAVI seems to be going towards improvement. This study is significant because the efficacy of CAVI will promote awareness among Educational practitioners, ESL, and EFL teachers to improve their vocabulary instructional ways.
\end{abstract}

Keywords: CALL, CAVI, Vocabulary Teaching, and learning

$\begin{array}{lll}\text { Received: 09.12.2020 } & \text { Accepted: 24.01.2021 } & \text { Published: 05.02.2021 }\end{array}$

\section{INTRODUCTION}

\section{Background of the study}

Computers have evolved massively in the past three decades. The usage of computers and technologies and other digital resources have offered many ways for humans to improve their lives in all walks of life and education is no exception. The computers, the internet, and its web-based resources have reasonably emerged as a dominant change maker. Therefore, CALL is one of the fields, technology has introduced in educational settings specifically for Language learners. The most established and widely accepted definition of CALL has been adopted for the study as it is in line with the aims and objectives of this study. Levy, (1997), succinctly defines CALL as, "the search for and study of applications of the computer in language teaching and learning" Hence, this definition admits the multifaceted role of CALL and its application in improving language performance. The next session will briefly discuss the emergence of CALL since its inception in the 1960s.

\section{History of CALL}

CALL made its way to educational pedagogy back in the 1960s. The earlier program of CALL merely contained language learning activities, such as vocabulary games (based on different vocabulary learning theories), speed-reading, simulation, and gap-filling, Levy,(1997) is cited in Ma \& Kelly, 2006). Ma \& Kelly, (2006) also cited a few researchers who tried to create CALL programs such as, Good fellow, 1994, Groot 2000; Boers, Eyckmans, and Stengers 2004. As a result, now the process of learning vocabulary is considered an integral ingredient of the CALL program.

To put it short; no language skill of L2 learners can be nurtured if its domain of vocabulary learning remains neglected. CALL i.e. Computer-assisted language learning has been receiving remarkable results as it has been seen as an integral part of ESL classrooms which facilitates the idea of integrating computers into language classrooms (Mahmoudi et al, 2012). Bagheri et al. (2012), discussed some historical phases of the developments of CALL. It can be traced out into three different developmental stages based on various teaching and learning approaches. These are: 


\section{Behavioristic Phase of CALL}

The first phase of CALL is also known as behavioristic CALL as it relied upon behaviorist theories of learning. Its principal objective was to achieve accuracy of language.

\section{Communicative Phase of CALL}

In this era, CALL programs hit a huge audience by the late 1970s due to the advent of personal computers (PC) and fostering developments of CALL. This approach contains exercises that encouraged students to extend their skills in learning structured \& unstructured lessons.

\section{Integrative Phase of CALL}

The beginning of a new phase doesn't reject previous approaches rather new approaches subsume into the previous one for the emergence of an innovative CALL program. This approach is divided is into two sub approaches based on two important technological advancements.

- Integrative CALL: Multimedia

- Integrative CALL: The Internet

\section{CALL TO CAVI - Conceptual Framework}

CALL has now become an integral part of the ESL classroom and since then Computer Assisted Vocabulary Instruction (CAVI) has been considered as the most common application of CALL.

CAVI is likely to use computers, computer applications, soft wares, or websites for vocabulary learning and instruction purposes, however, it is not integrated into Pakistani classrooms relatively. This study seeks to experiment with CALL in enhancing the vocabulary of ESL learners. The current study uses CAVI's framework, as shown in figure 1, taken from the study of Kocak, (1997).

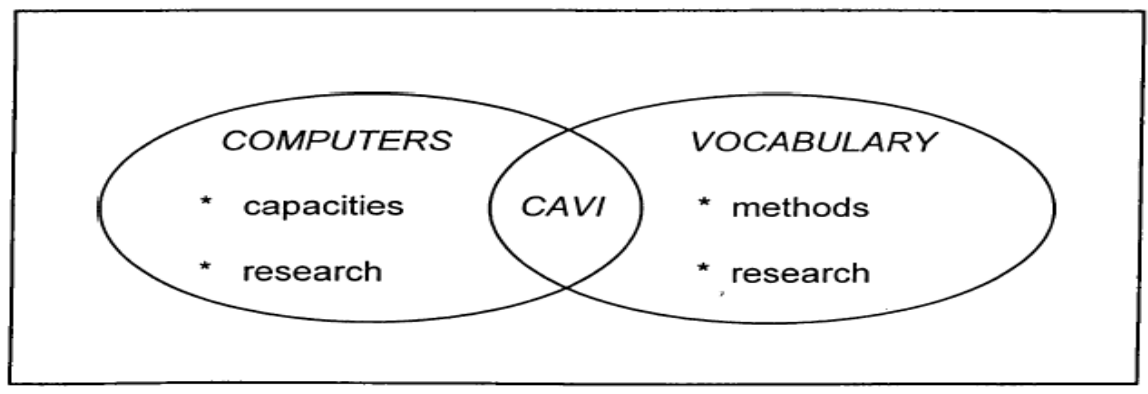

Figure 1

Computer Assisted Vocabulary Instruction (CAVI)

Figure 1

CAVI would be set in the setting of ESL where the study will undergo its due process to explore the results of using computers for vocabulary instructions.

Tokaç (2005) points out various CAVI researches in the studies whose CAVI programs foster vocabulary learning experiences while accommodating intentional and incidental vocabulary learning. Therefore, it can be assumed that CAVI's software trends and programs are aligned with vocabulary acquisition theories besides following lexical and level of knowledge process. Furthermore, CAVI tools include electronics/online dictionaries, concordance, hypertext annotations along with contextual information of word, picture, and videos. Hence, further research on CAVI will shed the light for teachers that whether it is good to make CAVI a choice for teaching vocabulary in a Pakistani context or not. This next section is now progressing to explore the rationale behind conducting this action research project.

\section{Rationale of the study}

Undoubtedly, CALL offers myriads of opportunities both for students and teachers. Teachers can play a crucial role in the integration of computer-based instruction in language teaching and learning practices. As, many institutions, including the current site of study, still have not determined the effective use of technology integration in language learning and teaching.

In a nutshell, this study is beneficial since there are very few studies discussing the utilization of computer programs as assisted materials for vocabulary instruction at the secondary level in Pakistan. 
Furthermore, it will suggest some possible avenues for the effective usage of technology in language education, along with providing additional topics and research methodologies for further studies.

The study is also significant because its results will reveal the attitude of learners towards using CALL for vocabulary learning. It will also reflect the dire need for integration between traditional teaching practices and technology-aided teaching of English as a second language.

\section{Aim and Objectives of the Study}

The current study intends to investigate the induction of Computer-assisted language learning i.e. CALL in current teaching practices of ESL classrooms in Pakistan.

The current study has the following objectives to achieve:

- To find out the secondary school learners' vocabulary level before and after CAVI.

- To explore the attitudes of secondary school learners towards CAVI.

\section{Research Questions}

This research study aims to target the vocabulary of language learners using CAVI. Therefore, it will address the following research questions:

$R Q 1$. What are the differences (if any) in the vocabulary proficiency of EPS secondary level learners in pre and post CAVI?

RQ2. What are the attitudes of EPS secondary level learners towards CAVI post CAVI treatment?

The next section talks about related literature concerning CAVI practices in the Pakistani context.

\section{LITERATURE REVIEW}

\section{CALL in Pakistan}

Mohammed Elwakeil, (2017) states "CALL develops the language learners' communication skills with convenience, accessibility, comfort and safety. They pick up language skills and improve efficiency faster. They can retain language skills longer and learn more about what they need. They are able to access materials to experience the interactions which would otherwise be difficult or impossible".Kousar et al., (2019) "Teaching English through Modern Technology" have been conducted in Mirpurkhas i.e. Sindh's Context. On the whole, it discussed different language skills including vocabulary practices. Specifically talking about vocabulary, Kousar et al., (2019) was of the view that providing a long list of words to students for rote memorization doesn't work effectively to enhance their vocabulary. There is a lack of data available regarding CAVI practices in Pakistan especially at the secondary level in Pakistan. They also opined that the appropriate use of technology promotes rich exposure to EFL learners. As Lewis (2000) has rightly pointed out the most significant task for L2 learners is retaining a large vocabulary list. Whereas in the Pakistani context; instructional strategies and the course material that have been used by public or private sectors face challenges. Due to these lacks, learners witness inequalities in learning various language skills at a different level. While maintaining the same view Ali et al., (2019) claimed that in spite of having facilities in public sectors educators are found to be struggling to use best-fitted teaching methodology or resources to embed technology in classrooms. They state, "The public sector institutions have given some facilities to their students yet they are unable to introduce latest and innovative teaching methods dipped in technology to teach students differently and effectively." In the same regard, Jamil et al (2014) study suggested that whether its private or public teachers their whole sole emphasis is upon English textbook which is often taken as sufficient to their learners' language needs. English classroom practices use loud reading repetition of words for vocabulary building and ignore modern techniques such as usage of multimedia or computer games. More than private sectors, public sector English Language teachers lag in skills to teach vocabulary as well as resources that can enrich their instructional process. Technological aid in the classroom is a rarely found phenomenon in Pakistan ESL classrooms and is limited to elite private sector schools. In 2015, a case study was conducted by Irshad et al, to addresses a very pertinent need for intervening in CALL programs and exploring their benefits to language pedagogy in Pakistan. The study suggested very encouraging outcomes of using CALL in advanced levels likewise observation indicated motivation, positive attitude, persuasion, and attentiveness towards learning L2. Moreover, the study also indicated that learners undertook more language learning activities than those they could enjoy in traditional practices in the ESL classroom. Therefore, it can be either inadequate resources, unsymmetrical distribution of resources, ignorance of secondary level education, or no teacher training program that has caused a lack of integration of technology in ESL classrooms in the Pakistani context. 


\section{Learners' attitudes towards CALL}

For language learning researchers, attitude is a controversial issue that is difficult to define. Psychologist takes an attitude as a person's expressions towards anything in favor or disfavor. Generally, the range for the attitude goes from extremely positive to extremely negative, while different individuals have different attitudes for the same entity at the same time Wood, (2000). Teo (2006) suggests students' learning and usage of technology for instruction in the classroom are very much influenced by attitudinal issues. That ensures the importance of attitude in the success or failure of implementing technology in the second or foreign language learning process. Tafazoli et al.,(2018) in their cross-cultural study on Iranian English language students' attitudes towards CALL find out, that due to the need for the digital era the positive attitudes of students are obvious. Moreover, the results of this study indicate that students acknowledge the vitality of computer skills in their professional and regular needs. In the above-mentioned study, researchers highlighted an important finding that there isn't any relation of variables such as gender, age, education or to be Iranian or not to the English language learners' attitudes towards CALL. Tsintavi (2017), investigated 90 high school students' attitudes and perceptions towards CALL. The researcher witnessed the enjoyment from the learners' side which led them towards the motivational level of learning more and more. The study revealed positive views by the learners for the usage of CALL in their language classrooms. Students viewed it as an opportunity to have flexibility and fun in learning through frequent and easy access and usage. Jalali \& Dousti, 2014 studied the relationship between students' attitudes and implementation of CALL. This study highlights that how the new generation promotes the use of technologies. The results also indicate that teachers' attitudes and exposure to computer-based activities are very much effective and influential for the change in students' attitudes. Therefore, promoting teachers' attitudes towards CALL can give better results for the learners as well and more computer exposure can lessen the hesitation and anxiety of the learners. Afshari et al. (2013) conducted a study on 100 undergraduate linguistics students to investigate the students' attitude towards CALL. The attitudes were found moderate towards CALL. They added that students' perception of computer attributes such as perceived usefulness and perceived ease of use had a direct and influential role, with which the students improved and enhanced their attitudes. Ayres (2002) conducted research on learners' attitudes towards CALL, the results concluded $80 \%$ consideration for the relevance of CALL to their needs, $70 \%$ found it useful and informative while $66 \%$ opinion opted that it should be included in their learning process. In the line with this investigation, those learners who see the importance of CALL are motivated as well. Moreover, this study highlighted another important factor that attitude can promote the adaptation of any initiative. Therefore, investigation and examination of learners' attitudes is a key factor at different levels. In the above study, several students found their experience good and advantageous and continued the usage of CALL, while those who were disappointed were not convinced about the continuation of the program.

On the whole, some important factors are crucial for the usage of technology such as perceived usefulness, easy usage, ability to adapt tools and other resources. These factors not only motivate but make learners autonomous.

\section{Effectiveness of CAVI}

This section aims to explore the studies conducted on the effectiveness of CAVI i.e. computer-assisted vocabulary instruction being done in various contexts. To begin with, CAVI includes the practices of vocabulary teaching and learning using technological aid. However, the studies, investigating the effects of CAVI in the Pakistani context are not appreciating in number.

Firstly, kocak (1997) examined the effectiveness of CAVI, and the results of this study suggested that the hypothesis set for this study seemed to be true. Consequently, the experimental group liked working with computers, in addition, this group learned and memorized vocabulary more than the other group i.e. control group. A later study by Tozcu \& Coady (2004) examined the effect of direct learning of wordlists through CALL on reading comprehension vocabulary knowledge and speed of word recognition. The results of the given comparative research study support that those participants who had undergone treatment witnessed significant change and control in their reading comprehension. It decreased their reaction time for word recognition and vocabulary knowledge gain than the control group.

Likewise, in previous studies, the results again learned out to be in the favor of the computerbased method so it can be argued that multimedia for instance animations or graphics contributed positively to vocabulary learning. Hence, it can be conceded that computer-based programs are a great motivational tool for vocabulary learning. 
Another empirical study by $\mathrm{Wu},(2015)$ advocates the efficacy of computer technology in terms of word retention for a longer time. Although, this study was conducted in the context of a self-directed computer learning system it validates the effectiveness of computer applications on the whole.

Likewise, Klimova \& Polakova, (2020) specifically studied learners' perceptions towards vocabulary learning via mobile applications (an alternative form of digital resource). This study was done in the context of the Czech Republic with university students as its participants. According to the results, learners supported technological aid because of its immediate and corrective feedback system.

To put it shortly; vocabulary instruction is a complex phenomenon that can be made more convincing, exciting, motivating, and fun-filled by integrating technological aid into pedagogical practices. Undoubtedly, the results of the above studies concerning CAVI are quite encouraging and the need for the current pedagogical paradigm. To address the above-mentioned questions, the currents study enroutes the following methodological procedure

\section{METHOD}

The current study follows the "Action Research" design (AR hereafter). Action research is an exclusive research strategy. Grant, (2007). It aims to revise practice and theory by acting and reflecting upon the focused issue.

\section{Participants}

Participants were sorted out from an Elite private school in Hyderabad, Sindh, Pakistan. This experimental study targets secondary level learners as the researcher herself have been teaching English at the research site for more than 05 years. The sampling used for this study is convenience sampling. Convenience sampling is the term that refers to a sampling approach where the choice of target contributors is primarily dependent on geographical proximity, handy accessibility, and approachability at a precise time following their consent and willingness to participate in the study. Creswell, (2012) states: "researcher selects participants because they are willing and available to be studied" (p. 145).

\section{Research Tools}

For this study, VST and Attitude Questionnaire have been used to evaluate the performance and attitude of learners respectively.

\section{Attitude Questionnaire}

An attitude questionnaire was distributed among 74 respondents to explore their attitude towards CAVI. Their attitudes were assessed by twenty items in the questionnaire. The researcher has adopted the questionnaire designed by (Mahmoudi et al, 2012).

\section{Vocabulary Size Test}

To collect quantitative data VST; designed by Nation and Beglar ( 2007) test will be adopted for pre and post-test. Concerning VST, they argue that this test measures a test taker's vocabulary size of decontextualized knowledge of the word. The pre-test and post-test data values were computed and analyzed separately. A paired sample t-test was used to compare the mean of the scores of the same learner's groups.

\section{CAVI Treatment}

"Vocabulary can be defined as the words of a language, including single items and phrases or chunks of several words which covey a particular meaning, the way individual words do. Vocabulary addresses single lexical items-words with a specific meaning(s)—but it also includes lexical phrases or chunks". Alfaki, (2015).

In order, to teach vocabulary, the researcher has carefully chosen vocabulary resources by considering few aspects such as, easy to use, websites and app mode, useable interface, freely accessible, highly ranked, and rated. As teachers and educational practitioners are inundated with digital resources and it needs careful consideration to choose resources while keeping their learners, targeted audience, and content to teach. CAVI treatment was given for a ten-week period after the conduction of the pre-test. While treatment, participants learned vocabulary through the following websites mainly.

$\checkmark$ https://www.teachingenglish.org.uk/

$\checkmark$ http://freerice.com/\#/english-vocabulary/1533

$\checkmark$ https://learnenglishteens.britishcouncil.org/

$\checkmark$ https://www.esolcourses.com/content/exercises/vocabulary/english-vocabulary.html 
$\checkmark$ https://eslflow.com/

$\checkmark$ https://www.vocaboly.com/

After the treatment, a post-test was conducted and pre and post results were analyzed to see the difference (if any). Later on, an attitude questionnaire was used to determine their likeliness towards CAVI applications.

\section{Reliability}

Drost (2011) defines reliability in a way that "the extent to which measurements are repeatable when different people measure on a different occasion, under different condition, supposedly with alternative instruments which measure the construct or skill".

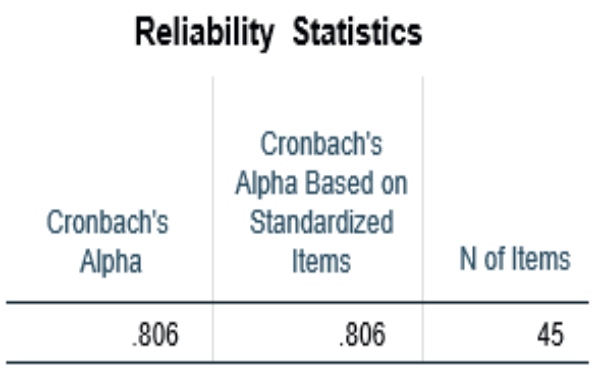

Table 3: Pre Test Reliability Results

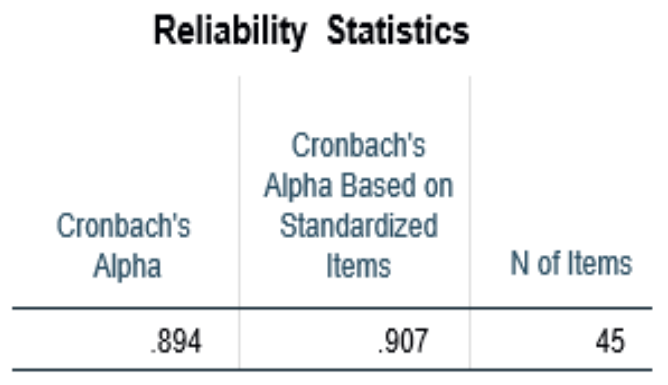

Table 4: Post Test Reliability Results

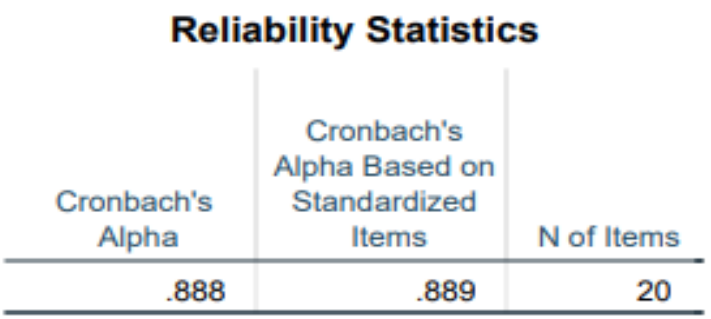

Table 5: Attitude Questionnaire Reliability Results

In the end, the Cronbach test was run to measure reliability on each set of data to check statistical value, for pre-test, it was 0.806 (table 3), for post-test 0.894 (table 4), whereas, for the attitude questionnaire, it was found to be 0.888 (table 5). Thus, results are said to be reliable in terms of statistics.

\section{RESULTS}

The study seeks to investigate the effects of CAVI treatment and to analyze the occurrences of attitudinal changes if there are any among learners. The table given below seeks to examine the overall result of CAVI by performing a sampled paired test. The result of the sample paired T-test is mentioned in table 01 :

Table 1

\begin{tabular}{|l|l|l|l|l|l|l|l|l|}
\hline \multicolumn{1}{|l|}{ Paired Sample Test } & & \multicolumn{5}{|c|}{$\begin{array}{l}\text { 95\% Confidence } \\
\text { interval of the } \\
\text { Difference }\end{array}$} & & \\
\hline Pair 1 & Mean & $\begin{array}{l}\text { Std. } \\
\text { Dev. }\end{array}$ & $\begin{array}{l}\text { Std. Error } \\
\text { Mean }\end{array}$ & Lower & Upper & t & df & $\begin{array}{l}\text { Sig. (2- } \\
\text { tailed) }\end{array}$ \\
\hline Pre-Post & -.17459 & .18481 & .02148 & -.21741 & -.13178 & -8.127 & 73 & .000 \\
\hline
\end{tabular}

The above table 01, illustrates the mean difference and significant value of pre and post vocabulary tests. The mean difference is -.17459 which indicates that the valuable difference between the performances before and after CAVI. The pre-post difference calculates the negative value which favors the post CAVI performance of learners and the significant impact of CAVI. 
Further, to analyze the significant difference $t$ and $p$ values have to be found out by running paired sample t-test on average scores. $\mathrm{T}$ and $\mathrm{p}$ values are often viewed as linked together inextricably. For, the current study the findings gather the calculation $t(73)=-8.127, p<.001$. The mean difference here doubles the magnitude of the $t$ value showing absolute statistical difference pre and post-treatment. The two-tailed significant p-value is .000 as shown in the results in the above-mentioned table 1 which is taken as $\mathrm{p}<.001$, which approves the occurrence of notable difference between the learners' performance with an effect of CAVI. The value of $\mathrm{p}$ for the current project according to the existing literature makes up a significant difference between the two sets of values.

In other words, the application of Paired sample t-Test analysis revealed a positive and significant difference between the pre-test and post-test performances of learners. The overall mean for the score of the pre-test is reported to be .7111 raised to .8862 with a 73 degree of freedom, which is an acceptable and logical value of independent subject values. Hence, it can be concluded that vocabulary treatment through computer-aided resources impacts positively learners.

\section{Statistical Analysis of Attitudinal Changes towards CAVI}

Based on the results this section attempts to analyze the data for each variable i.e. of CAVI, efforts put by the learners to use CAVI resources, Learners' self-perception towards CAVI, and motivation towards CAVI, one by one respectively with the help of descriptive analysis of means of each variable contain five (05) items mentioned below:

\section{Descriptive analysis of means for each variable of attitudinal changes towards CAVI}

Table 2

\begin{tabular}{|l|l|}
\hline Variables & Over-all Mean \\
\hline Usage & 3.76 \\
\hline Effort & 3.71 \\
\hline Self-Perception & 3.77 \\
\hline Motivation & 3.88 \\
\hline
\end{tabular}

The above-mentioned table 2 summarizes the overall means gathered for each variable set for the attitudes of students towards the practices of CAVI. The first variable calculated the data for the learners' attitudes towards the usage of CAVI applications that gathered the overall mean of 3.76, which is shifting from moderate to a high level. It indicates the satisfactory attitudes from learners as they found CAVI's usage interesting and enjoyable. The value of the overall mean for the effort implied by learners towards CAVI is 3.71, in terms of ease in using CAVI as compared to traditional vocabulary lessons. Hence, it is also above the moderate level and signals the willingness of efforts and involvement in their attitudes. Students perceived positively for the third variable which is self-perception, calculates the overall mean of 3.77, ranges towards high value. Students considered learning through CAVI is effective and influential for vocabulary knowledge. The overall mean value for the motivation towards CAVI was calculated higher than other variables which are 3.88. It indicates a high level of positive attitudes. Students were motivated for CAVI and found it engaging and useful.

The gathered data favors the effectiveness of CAVI, as the overall attitudes are found up to a high level. Students reflected positively on each variable. The data ensures that the CAVI practices can change the success progress and achieve the shift in attitudinal issues. 


\section{Graphical representation of attitudinal change towards CAVI as a user}

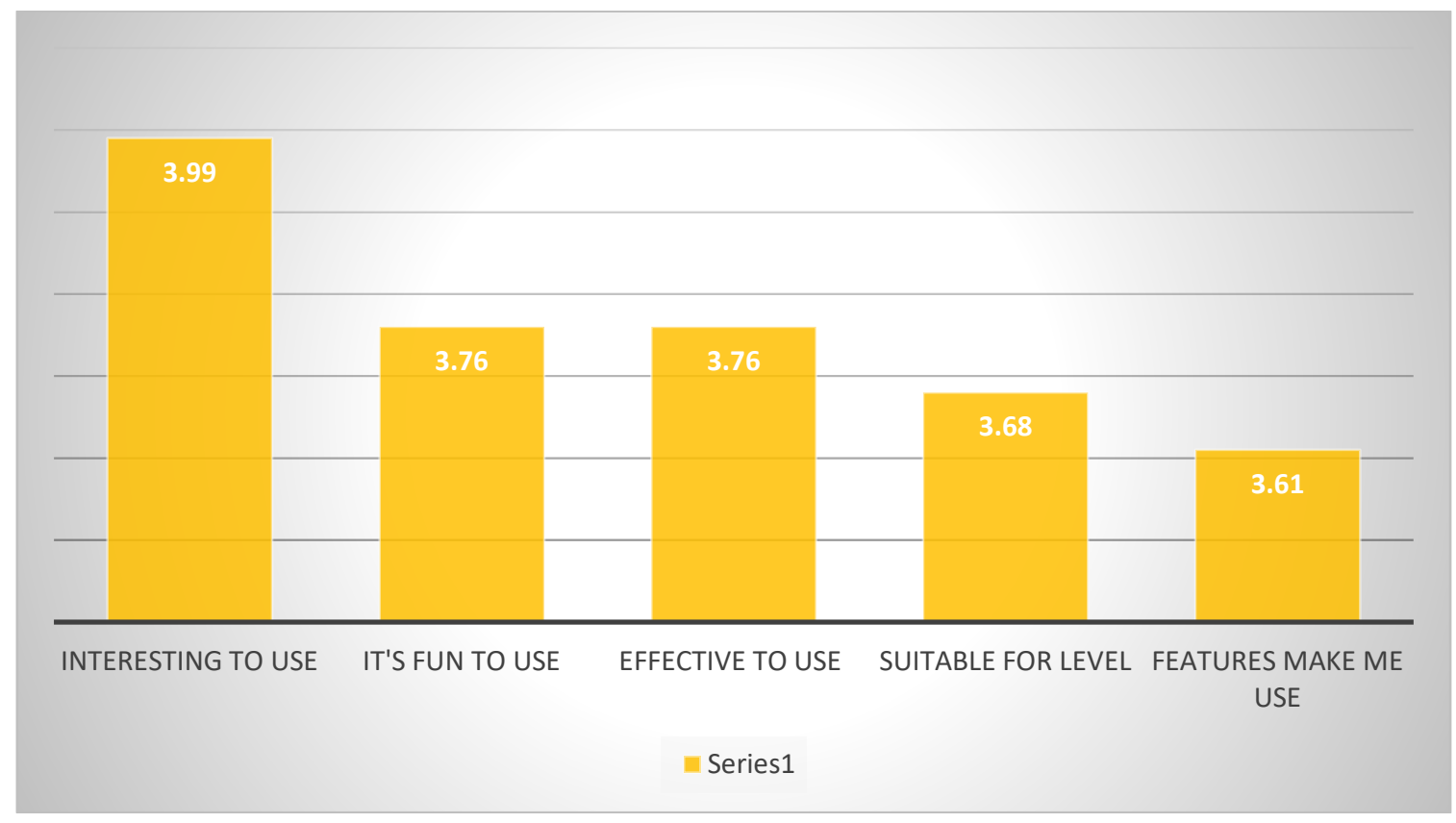

\section{Graph 1}

This section derives the result in graphical representation reflecting the change in attitude as a user towards CAVI. The comparative analysis of variables for each mean has been represented graphically. It shows the overall mean value of 3.76, which is going from moderate to a high level. It indicates that learners enjoyed the experience of CAVI in terms of effectiveness, appropriateness, engagement, and interest. Its usage builds up their interest in learning vocabulary through the computer.

\section{Graphical Representation of Effort implied in learning Vocabulary (in terms of ease as compared to traditional vocabulary lessons)}

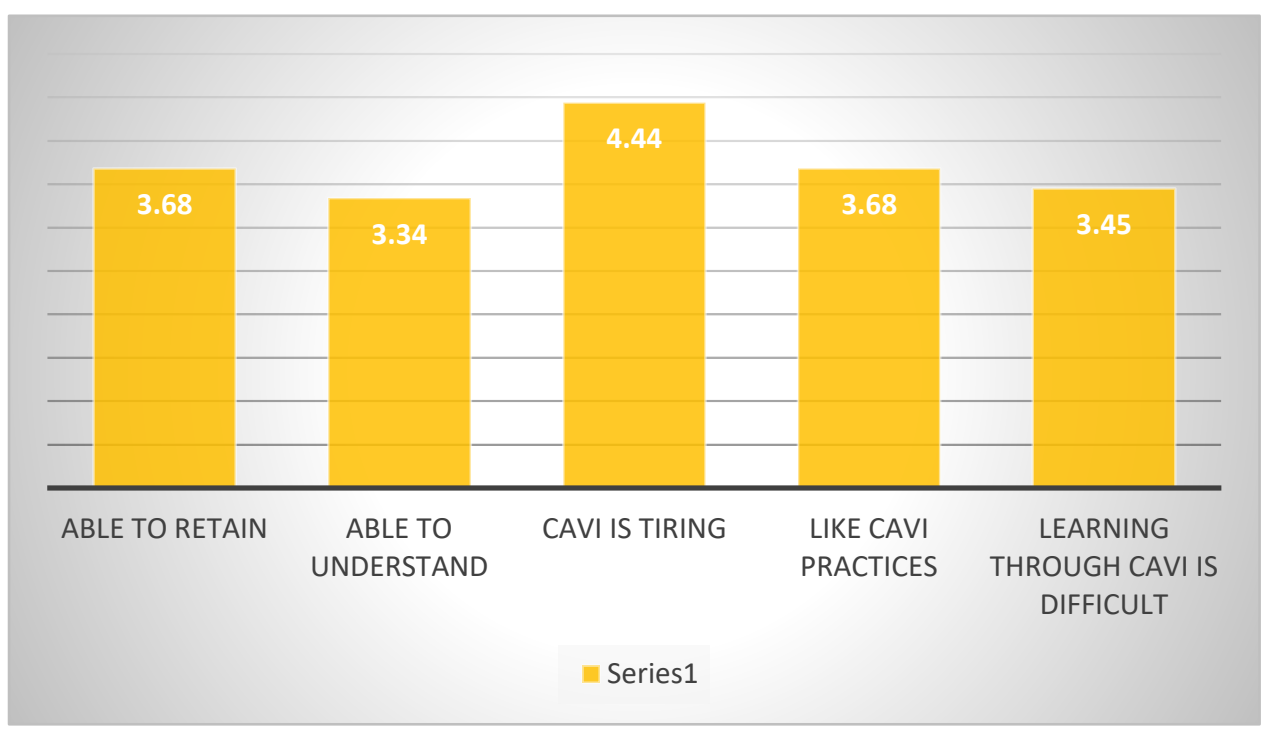

Graph 2

The above-mentioned graph represents the level of achievement for the items given in the category of efforts implied by learners for the learning of vocabulary through CAVI. The overall mean for this variable was calculated as 3.71, which is above the moderate level. It indicates that students' attitudes were above the neutral level for the self-efforts they implied during the learning process through CAVI and students were involved willingly in the digital learning process. The third and the last item was reported negatively and coded reversely, which gathered the data in the favor of CAVI. 


\section{Graphical representation of Self-Perception towards CAVI}

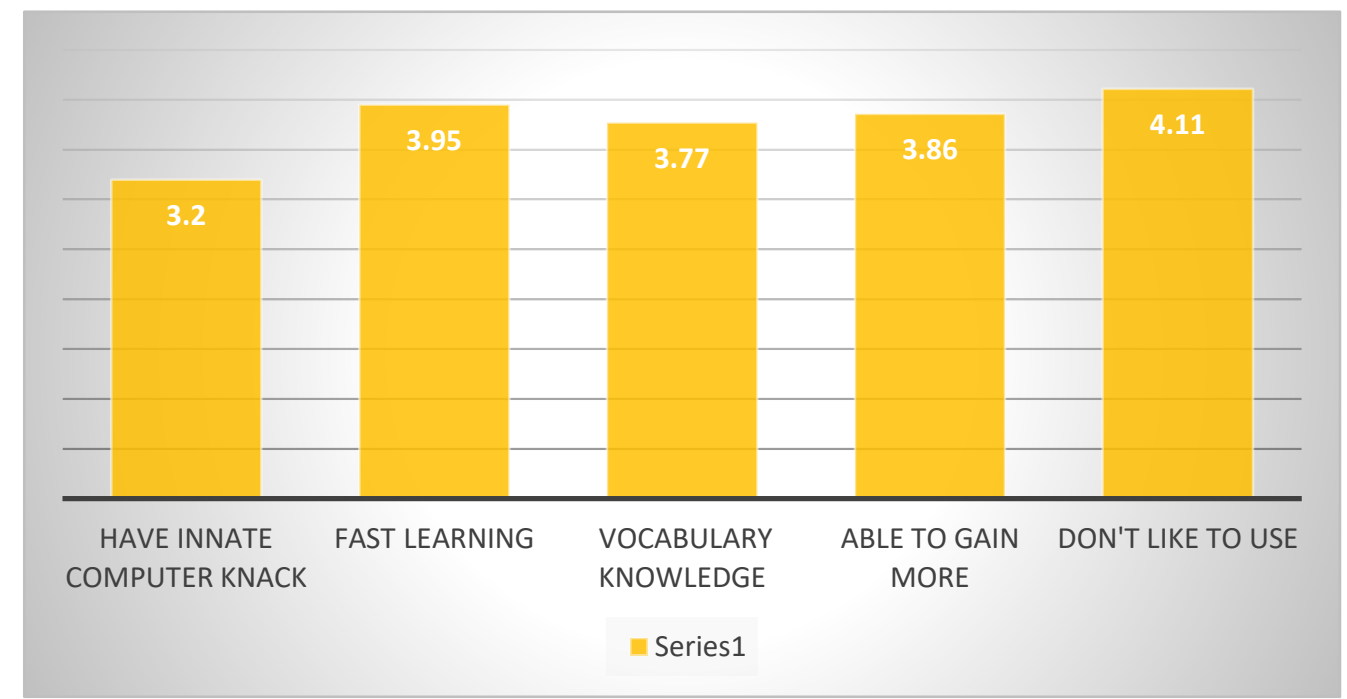

\section{Graph 3}

The above graph presents the self-perception of learners, which calculated the mean difference of the entire category as 3.77. It indicates that the attitudinal shift is falling from moderate to a high level. In short, it can be interpreted in terms of students' assumptions of CAVI as a fast learning resource for those who have a technology- a friendly attitude. The last item is negative, thus coded in reverse, reflecting disapproval of the fact that they don't like CAVI Practices.

\section{Graphical representation of Motivation towards CAVI}

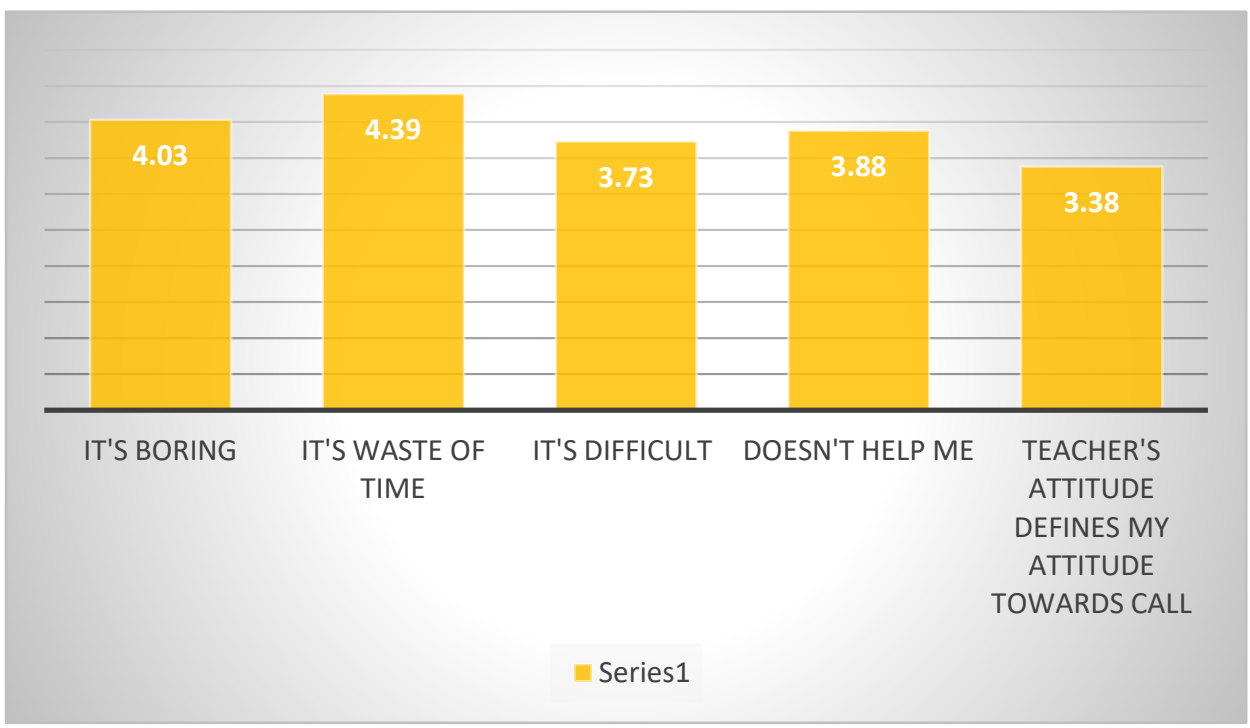

\section{Graph 4}

The above graphical chart presents the motivational inclination of learners. As items 01 to 04 in this chart are the negative statement, Hence, it shows the disagreement regarding the statement while proving the eagerness of learning vocabulary through websites. Its overall mean is 3.88 which is the highest mean among all categories. Therefore, it shows a strong motivational derive of students towards CAVI. 


\section{DISCUSSION}

This section aims at discussing the current findings with the existing literature to validate them. It will present the relevance of current findings with the patterns that emerged in previous studies.

\section{Discussion of Findings of RQ1}

The findings are in line with many studies. Beginning with Kocak (1997), whose study resulted in favoring CAVI practices. As the comparative study of the experimental and control group delivered a significant difference in the performance of the experimental group underwent CAVI and control group studied with the text materials only. The study was conducted in the Turkish Context of EFL learners. Likewise, a study was conducted by Gorjian et al., (2011) to measure the impact of computerassisted vocabulary learning retention among high and low achievers. Therefore, an immediate post-test and a delayed post-test, to check the effectiveness of instruction of retention was conducted. The results reveal that high achievers benefitted from CALL instructions whereas, low achievers remained beneficiary during the vocabulary retention period. The findings of this study also support the outcome of the current study done in the Pakistani context.

Likewise, Naraghizadeh \& Barimani's, (2013) study also seems to fall in line with the findings of this study. Their study "The Effect of CALL on the Vocabulary Learning of Iranian EFL Learners" traces the significant difference between the performance of experimental and control group learners. An experimental group who learned vocabulary under CALL settings outperformed the other group.

Similarly, Nejati et al (2018) studied the effects of CAVI versus teacher-led instructional method on intermediate and pre-intermediate Iranian learners. The results of this experimental study favored the effects of CAVI as compared to both groups led by teacher based instructional ways. The study suggests the reasons for this success that it happened due to various reasons including individualized learning experience where learners were more in control over their learning pace, that's how they felt more autonomous and motivated to perform. This finding facilitated the entire idea of the study confirming not only the efficacy of CAVI for vocabulary teaching but proved to be a motivational derive for learners, which supports the findings of RQ 2 as well.

The pattern that emerged from this study supports the idea of CAVI, which is also visible in the study of Shokrpour et al., (2019). The study had somehow similar research questions to address. The study supported the CALL instruction claiming it had a significant effect on EFL learners of Iran. To add more, the data presented a major difference in the mean scores in the experimental and control group. Both groups had similar mean scores individually but in the post-test performance, there was found to have a noticeable difference.

Hirschel \& Fritz, (2013), explored the short-term effectiveness along with the long-term effectiveness of two popular yet rarely investigated strategies of vocabulary learning. i.e. Learning vocabulary from a notebook and Learning vocabulary using CALL applications with spaced repetitions. As suggested by the outcomes, some statistically significant results were spotted, in terms of the scores of vocabulary knowledge in pre and post-test for both groups of learners. For longer vocabulary retention CALL group performed better, which supports the results of the study at hand.

Another study by Pamintuan et al.,(2018) is an attempt to induct technological aid into the classroom by bringing WeChat application to teach vocabulary. It concludes that learners using WeChat exhibit improved vocabulary performance (pre and post) including the motivation of the digitallyinclined learners in learning Chinese vocabulary.

To conclude the discussion by validating the current study's results with the results of a quasiexperimental study by Basoz \& Cubukcu, (2014). Although the study was conducted on tertiary learners even then, it echoed somehow similar results. CALL group vs CLT group (Communicative Language teaching) were given vocabulary lessons through CALL and CLT strategies respectively. Both groups delivered vocabulary gain, However, no major difference was recorded in the post-performance of each group.

In short, there is a need to embrace new teaching methods in ELT as (Khokhar et al., 2020) suggest that modern methods of teaching are flexible and seem to be adequately fitting to the needs and learning goals of the learners. Therefore, choice and application of teaching resources influence learners' motivation level and encourage them to be more independent in their learning to become inspired learners.

This section wraps up the discussion of RQ1 results and now heads up to the discussion of RQ2. 


\section{Discussion of Findings of RQ2}

Learners' attitude towards CAVI in the "reflect" phase, was meant to analyze the attitudinal changes resulting after CAVI. Participants received a short questionnaire of 20 items with 5 scale Likert items to draw students' attitude patterns after the CAVI project.

The current patterns resulting from this experimental study are in line with the various studies. To sum up the results of RQ3, these studies are discussed in line with the existing results of the study.

This study reinforces the same idea that occurred in the results of Kocak (1997) study of investigating the effectiveness and attitudes of Turkish EFL learners. Learners exhibited positive responses in terms of using a computer to learn L2 vocabulary. Besides they feel motivated and fun while practicing lessons on computers. According to them, computers enable them to retain or learn more effectively and easily. Esit, (2011) study reported similar results in relation to vocabulary development. It had "positive effects on both learners' vocabulary learning and their attitudes towards the use of an intelligent computer-assisted language learning application in the classroom".

Likewise, Önsoy's (2004) study addressed the attitudinal differences in the teachers and learners both on the tertiary level. The results indicated an overall positive attitude to get indulged in CALL practices. Also, it suggests that the more and sooner students are made to encounter digital resources the better they will get in terms of language proficiency and computer knack. This finding is relevant to one of the outcomes of this study that students with more computer operating skills are keener to have their vocabulary lessons on CAVI applications.

The study demonstrated that the students" attitudes towards computers and computer-assisted learning define their attitude towards CALL. The learners who consider themselves to be proficient and integrated with computers have positive attitudes towards CALL

In short, Ali et al., (2012) presented the gist of the study along with citing Iwanski, (2001); Kukulska-Hulme, (1998) "it lends empirical support to the idea that computers can promote positive learning attitudes compared to the conventional methods". This emerged pattern is used here to finally conclude the results of the study by validating them with the existing literature in the present body of knowledge. In response to learners' attitude towards usage of CAVI practices, (Bahadorfar, 2014) investigated learners' attitude towards learning vocabulary in CALL environments. The findings suggest that it is not only an "effective student-centered" method but also reflects a motivational inclination and positive attitude towards Vocabulary learning through digital resources. These findings resonate appropriately with the findings of the study at hand.

Similarly, Abbasi \& Hashemi, (2013), studied the effects of inducting mobile phones to enhance vocabulary learning. According to the results of their study, students were found to develop a favoring attitude in learning vocabulary through technology-based resources.

To put up with the patterns that emerged regarding the usage of CAVI, the data favors the learning attitude of learners for CAVI due to its features and this corresponds to the outcome of Hufton (2006) claiming the usefulness of CALL features seems to be benefitting learners and they feel more in charge of their learning. In addition, (Vasu \& Dhanavel, 2015) study echoed something similar which falls under the findings of this study. It suggests that learners' willingness and choice for learning vocabulary is social media and technological applications.

To conclude, the results of this study also comply with the outcomes of Hermagustiana \& Rusmawaty, (2017) which supports internet oriented applications to promote vocabulary knowledge. As the internet provides easy-to-search resources for teachers in fact for learners too which enables learners to learn English vocabulary in a real-life context.

\section{CONCLUSION}

Vocabulary learning is a key aspect of any language learning process which elevates the learner's language proficiency in all other linguistic domains. The results are drawn from this study which is set to investigate the effectiveness of CAVI and their attitude towards it. Hence, from the vocabulary test data, it can be concluded that CAVI's treatment results in enhancing learners' vocabulary knowledge. Therefore, the study supports the idea to integrate the computer as a vocabulary instructional tool along with its digital or web-based resources. On the other hand, the data gathered from an attitude questionnaire confirms a positive attitudinal change in a given time period of 10 weeks. The participants of this study get influenced as all categories and variables have statistically been inclining towards moderate to a high level.

To sum up, with the implications, the findings of this study are beneficial for the secondary level learners to help them discover the ways and resources that can be effective even outside the classroom in engaging them in a vocabulary development process. 
This can help educational practitioners to promote learners' autonomy while learning vocabulary.

For the administrative implications, this study advocates that ESL teachers should be trained so that they should not let technological advancement pass by without utilizing it to serve vocabulary teaching to be accomplished.

More importantly, this study does not refute the traditional practices entirely, that's why further research can be made to investigate vocabulary practices at larger scales addressing more public and private sector schools

The limitations of this experimental study may affect its generalization for different level learners either primary or tertiary. Furthermore, it cannot be extended to other schools and areas of Sindh, Pakistan.

\section{REFERENCES}

Abbasi, M., \& Hashemi, M. (2013). The impact/s of using Mobile phone on English Language Vocabulary Retention. Irjabs.com; International Research Journal of Applied and Basic Sciences. http://www.irjabs.com/files_site/paperlist/r_710_130328101509.pdf

Afshari, M., Ghavifekr, S., Siraj, S., \& Jing, D. (2013). Students' Attitudes towards Computer-assisted Language Learning. Procedia - Social and Behavioral Sciences, 103, 852-859. https://doi.org/10.1016/j.sbspro.2013.10.407

Ahmadian, M., Amerian, M., \& Goodarzi, A. (2015). A Comparative Study of Paper-based and Computerbased Contextualization in Vocabulary Learning of EFL Students. Advances in Language and Literary Studies, 6(2). https://doi.org/10.7575/aiac.alls.v.6n.2p.96

Alfaki, I. (2015). Training and Development UK ( Published by European Centre for Research vocabulary input in English language teaching: assessing the vocabulary load in spine five. International Journal of English Language and Linguistics Research, 3(1), 1-14. http://www.eajournals.org/wpcontent/uploads/Vocabulary-Input-in-English-Language-Teaching-Assessing-the-VocabularyLoad-in-Spine-Five.pdf

Ali, M. M., Mahmood, M. A., Anwar, M. N., Khan, L. A., \& Hussain, A. (2019). Pakistani Learners' Perceptions Regarding Mobile Assisted Language Learning in ESL Classroom. International Journal of English Linguistics, 9(4), 386. https://doi.org/10.5539/ijel.v9n4p386

Ali, Z., Mukundan, J., Baki, R., \& Fauzi Mohd Ayub, A. (2012). Second Language Learners' Attitudes towards the Methods of Learning Vocabulary. English Language Teaching, 5(4). https://doi.org/10.5539/elt.v5n4p24

Ayres, R. (2002). Learner Attitudes Towards the Use of CALL. Computer Assisted Language Learning, 15(3), 241-249. https://doi.org/10.1076/call.15.3.241.8189

Bagheri, E., Roohani, A., \& Ansari, D. N. (2012). Effect of CALL-based and Non-CALL Based Methods of Teaching on L2 Vocabulary Learning. Journal of Language Teaching and Research, 3(4). https://doi.org/10.4304/jltr.3.4.744-752

Basoz, T., \& Cubukcu, F. (2014). The effectiveness of computer assisted instruction on vocabulary achievement. Mevlana International Journal of Education,4(1), 44-54. https://doi.org/10.13054/mije.13.77.4.1

Bahadorfar, M. (2014). The effect of computer assisted language learning on EFL learners attitudes towards learning English in https://doi.org/http://hdl.handle.net/10603/110448

Baten, Lutgarde \& Ricker, M \& Deceuninck, I \& Torre, M \& Montero-Fleta, Begona \&

Sabater,C \& Salom, L \& Guillot, C \& Monreal, C \& Turney, E \& Reviews, Book. (1999). WebSiteStories (WST): $\quad$ Evaluating works of art. https://www.researchgate.net/publication/277282913_WebSiteStories_WST_Evaluating_works_ of_art

Creswell, J. W. (2012). Educational Research: Planning, conducting, and evaluating quantitative and qualitative research (4th ed.). Allyn \& Bacon. https://www.pdfdrive.com/educational-researchplanning-conducting-and-evaluating-d16448388.html

Derlina,, Aisyah,, Bukit, N., Sahyar,, Hassan, A., (2020). Blended Learning in English and English-Medium Physics Classes Using Augmented Reality, Edmodo, and Tinkercad Media. TESOL International Journal,15 (3), 111-136.

Drost, E., A. (2011). Validity and reliability in social science research. Education Research and Perspectives, 38 (1), 105-124. 
Eagly, A. H., \& Chaiken, S. (1998). Attitude structure and function. In D. T. Gilbert, S. T. Fiske, \& G. Lindzey (Eds.), The Handbook of Social Psychology (4th ed., pp. 269-322). Oxford University Press.

Ebadi, S., \& Bashiri, S. (2018). Investigating EFL Learners' Perspectives on Vocabulary Learning Experiences through Smartphone Applications. Teaching English with Technology, 18(3), 126-151. https://eric.ed.gov/?id=EJ1186367

Esit, Ö. (2011). Your verbal zone: an intelligent computer-assisted language learning program in support of Turkish learners' vocabulary learning. Computer Assisted Language Learning, 24(3), 211-232. https://doi.org/10.1080/09588221.2010.538702

Gorjian, B., Moosavinia, S. R., Ebrahimi Kavari, K., Asgari, P., \& Hydarei, A. (2011). The impact of asynchronous computer-assisted language learning approaches on English as a foreign language high and low achievers' vocabulary retention and recall. Computer Assisted Language Learning, 24(5), 383-391. https://doi.org/10.1080/09588221.2011.552186

Grant, S. (2007). Learning through 'being' and 'doing'. Action Research, 5(3), 265-274. https://doi.org/10.1177/1476750307081017

Hassan, A., Kazi, A.S., Shafqat, A., Ahmed, Z., (2020). The Impact of Process Writing on the Language and Attitude of Pakistani English Learners. The Asian EFL Journal,27 (4.3), 260-277.

Hassan, A., Mitchell, R., \& Buriro, H. A. (2020). Changes in uses of salutations in British English. International research journal of management, IT and social sciences, 7(1), 197-204.

Hassan, A. (2016). Assimilation and incidental differences in Sindhi language. Eurasian Journal of Humanities, 2(1).

Hassan, A. (2018, January 5). Allaboutcorpora. Retrieved from https://allaboutcorpora.com: https://allaboutcorpora.com/rising-star-ahdi-hassan-pakistani-languages-corpora

Hermagustiana, I., \& Rusmawaty, D. (2017). The Use of Technology for Vocabulary Instruction in EFL Classrooms: Support and Challenges. Advances in Intelligent Systems Research (AISR). https://download.atlantis-press.com/article/25902606.pdf

Hirschel, R., \& Fritz, E. (2013). Learning vocabulary: CALL program versus vocabulary notebook. System, 41(3), 639-653. https://doi.org/10.1016/j.system.2013.07.016

Hufton, C. (2006). Longman English Interactive. Www.Tesl-Ej.org. http://www.teslej.org/wordpress/issues/volume9/ej34/ej34m2/

Irshad, S., \& Ghani, M. (2015). Benefits of CALL in ESL Pedagogy in Pakistan: A Case Study. ELF Annual Research Journal, 17, 1-22.

Itmeizeh, M., \& Hassan, A. (2020). New Approaches to Teaching Critical Thinking Skills through a New EFL Curriculum. International Journal of Psychosocial Rehabilitation, 24(07).

Jamil, S., Majoka, M. I., \& Khan, M. S. (2014). A Study of Vocabulary Building in English Language Curriculum at Primary Level in Pakistan. Journal of Elementary Education, 24(1), 31-45.

Janebi Enayat, M., Amirian, S. M. R., Zareian, G., \& Ghaniabadi, S. (2018). Reliable Measure of Written Receptive Vocabulary Size: Using the L2 Depth of Vocabulary Knowledge as a Yardstick. SAGE Open, 8(1), 215824401775222. https://doi.org/10.1177/2158244017752221

Jalali, S., \& Dousti, M. (2014). Attitudes of Iranian EFL learners towards CALL: The effect of treatment length investigated. Malaysian Journal of ELT Research, 10(1), 46-62. https://www.journals.melta.org.my/index.php/majer/article/download/132/47

Khokhar, S., Pathan, H., Arslan Raheem, M., \& Ajmal, M. (2020). English language Teaching Methods: Their Development, Implication and Application in Language Classroom. Asian EFL Journal, 27(5.1), 220-238. https://www.asian-efl-journal.com/tag/volume-27/

Kocak, N. C. (1997). The effectiveness of computer assisted language learning (CALL) in

vocabulary instruction to Turkish EFL students. https://core.ac.uk/download/pdf/52928345.pdf

Kousar, S., Sartaj, S., Shah, S. W., \& Lohar, S. A. (2019). Teaching English Through Modern Technology: A Study of Private Language Centers, Sindh Pakistan. Education and Linguistics Research, 5(1), 113. https://doi.org/10.5296/elr.v5i1.14575

Klimova, B., \& Polakova, P. (2020). Students' Perceptions of an EFL Vocabulary Learning Mobile Application. Education Sciences, 10(2), 37. https://doi.org/10.3390/educsci10020037

Lin, L.-F. (2010). English Learners' Incidental Vocabulary Acquisition in the Video- based CALL Program Asian EFL Journal: Asian EFL Journal. Www.Asian-Efl-Journal.com. https://www.asian-efljournal.com/main-editions-new/english-learners-incidental-vocabulary-acquisition-in-the-videobased-call-program/

Levy.M. (1997). Computer assisted language learning: Context and conceptualization.

Ma, Q., \& Kelly, P. (2006). Computer assisted vocabulary learning: Design and evaluation. Computer Assisted Language Learning, 19(1), 15-45. https://doi.org/10.1080/09588220600803998 
Mahmoudi, E., Samad, A. bt A., \& Razak, N. Z. Bt. A. (2012). Attitude and Students' Performance in Computer-Assisted English Language Learning (CAELL) for Learning Vocabulary. Procedia - Social and Behavioral Sciences, 66, 489-498. https://doi.org/10.1016/j.sbspro.2012.11.293

Mahmoudi, H. M., \& Hassan, A. CHALLENGES AND ISSUES OF LANGUAGE USE BETWEEN MONOLINGUAL AND MULTILINGUAL SOCIETIES. Dimension Journal of Humanities and Social Sciences, 1-19.

Mohammed Elwakeil, M. (2017). The Role of CALL in Vocabulary Acquisition through the Application of Learning Strategies. International Journal on Studies in English Language and Literature, 5(10). https://doi.org/10.20431/2347-3134.0510008

Manel, M., Hassan, A., \& Buriro, H. A. (2019). Learners' Attitudes towards Teachers' switching to the mother tongue (The Case of Secondary school learners in Algeria). Indonesian TESOL Journal, 1(1), 9-26.

Mirza, Q., Pathan, H., Khatoon, S., Hassan, A., (2021). Digital Age and Reading habits: Empirical Evidence from Pakistani Engineering University. TESOL International Journal,16 (1), 210-136.

Naraghizadeh, M., \& Barimani, S. (2013). The Effect of CALL on the Vocabulary Learning of Iranian EFL Learners. Journal of Academic and Applied Studies (Special Issue on Applied Linguistics), 3(8), 1-12. http://academians.org/Articles/August2013-1.pdf

Nation, I. S. P., \& Beglar, D. (2007). A Vocabulary Size Test. The Japan Association for Language Teaching, 31, 9-12.

Nejati, E., Jahangiri, A., \& Salehi, M. R. (2018). The Effect of Using Computer-Assisted Language Learning (CALL) on Iranian EFL Learners' Vocabulary Learning: An Experimental Study. Cypriot Journal of Educational Sciences, 13(2), 351-362. https://eric.ed.gov/?id=EJ1183258

Önsoy, S. (2004). Students' and Teachers' attitudes towards the use of Computer-Assisted language learning at the preparatory school of Celal Bayar university a master' $s$ thesis. https://core.ac.uk/download/pdf/52939839.pdf

Pamintuan, C. F., Mallari, D. G., Garcia, N. T., Galang, J. P., \& Buduan, R. M. B. (2018). The Use of WeChat Application on CFL Learners' Vocabulary Acquisition. TESOL International Journal, 13(4), 26-38. https://www.elejournals.com/download?code=5c2cd4952ebba

Shokrpour, N., Mirshekari, Z., Moslehi, S., \& Popescu, M. (2019). Learning vocabulary electronically: Does computer assisted language learning (CALL) instruction have any impacts on Iranian EFL learners? Cogent Education, 6(1). https://doi.org/10.1080/2331186x.2019.1702827

Supriyatno, T., Susilawati, S., Hassan, A., (2020). E-learning development in improving students' critical thinking ability. Cypriot Journal of Educational Sciences, 15(5), 1099-1106. https://doi.org/10.18844/cjes.v15i5.5154

Tafazoli, D., Gómez Parra, M. E., \& Huertas Abril, C. A. (2018). A Cross-Cultural Study on the Attitudes of English Language Students towards Computer-Assisted Language Learning. Teaching English with Technology, 18(2), 34-68. https://eric.ed.gov/?id=EJ1177704

Teo, T. (2006). Attitudes toward computers: A study of post-secondary students in Singapore. Interactive Learning Environments, 14(1), 17-24. https://doi.org/10.1080/10494820600616406

Tokaç, A. (2005). A comparison of Computer-Assisted vocabulary instruction and teacher led vocabulary instruction .http://www.thesis.bilkent.edu.tr/0002840.pdf

Tozcu, A., \& Coady, J. (2004). Successful Learning of Frequent Vocabulary through CALL also Benefits Reading Comprehension and Speed. Computer Assisted Language Learning, 17(5), 473-495. https://doi.org/10.1080/0958822042000319674

Tsintavi, M. (2017). Students' Attitudes and Perceptions towards Computer-Assisted Language Learning. Journal of Applied Linguistics and Language Research, 4(3), 65-93. https://www.jallr.com/index.php/JALLR/article/view/547

Us Saqlain, N., Shafqat, A., Hassan, A., (2020). Perception Analysis of English Language Teachers about Use of Contextualized Text for Teaching ESP. The Asian ESP Journal,16 (5.1), 275-299.

Vasu, S., \& Dhanavel, S. P. (2015). Understanding the attitude of ESL learners to vocabulary learning. Calidoscópio, 13(2). https://doi.org/10.4013/cld.2015.132.08

Windeatt, S. 1986. Observing CALL in action. In Leech, G. and Candlin, C. N.(eds.), Computers in English language and research. New York: Longman.

Wood, W. (2000). Attitude Change: Persuasion and Social Influence. Annual Review of Psychology, 51(1), 539-570. https://doi.org/10.1146/annurev.psych.51.1.539

$\mathrm{Wu}$, J. (2015). Effects of CALL on Self-directed FL Vocabulary Learning. SiSAL Journal. http://sisaljournal.org/archives/jun15/wu 